Int. J. Dev. Biol. 52: 415-426 (2008)

doi: $10.1387 / \mathrm{ijdb} .072551 \mathrm{jb}$

\title{
Puzzles of mammalian fertilization - and beyond
}

\author{
J. MICHAEL BEDFORD* \\ Dept. of Obstetrics and Gynecology and Center for Reproductive Medicine and Infertility, Weill Medical College, \\ Cornell University, New York, NY, USA
}

\begin{abstract}
A complexity imposed on the events of conception during the evolution of eutherian mammals is reflected not only in the placenta but also in a series of gamete-related novelties that involve the design of sperm and eggs, their interactions leading to fertilization, epididymal function, and even the scrotal state. While their functional significance has been difficult to determine, I suggest on the basis of present evidence that the genesis of these novel features relates ultimately to changes in the egg associated with nidation, that they imply a new fertilization strategy, and that most are causally linked - a major first 'domino' being the formidable zona pellucida. The eutherian zona pellucida stands out by virtue of an elastic resilience and thickness which allow it to stretch around the expanding blastocyst. However, this quality of the zona together with its relative protease-insensitivity creates a physical challenge which appears to have determined the design of the sperm head, its behaviour at fertilization, and indirectly even the pattern of sperm maturation in the epididymis. In turn, that pattern appears to have evoked the development of the sperm storage function of the cauda region, with both sperm capacitation and the scrotal state as ultimate legacies of this. Coincidentally, the vulnerability of the small yolkless egg to polyspermy appears to have selected for a unique parsimonious pattern of sperm transport in the Fallopian tube, and possibly for the role of the cumulus oophorus as a sperm sequestering device. These ideas are supported generally by evidence from marsupials, as well as by the deviant patterns seen in some insectivorous mammals.
\end{abstract}

KEY WORDS: zona pellucida, sperm head structure, epididymis, cumulus oophorus, sperm capacitation

\section{Introduction}

Fertilization research has long been conducted primarily in animals whose gametes are relatively easy to obtain and manipulate, but this was more difficult at first in the case of mammals. Notwithstanding Sobotta's accounts of fertilization in the mouse already in the 1890's, and descriptions of mammalian sperm and eggs years before that, the small gem Problems of Fertilization (Lillie, 1919) makes clear that mammals were then only minor players in efforts to understand fertilization. Subsequently, before World War II, the morphological aspects especially were pursued further in such as the rabbit, bat, ferret, and some rodents, and in 1936 Gregory Pincus published a monograph - The Eggs of Mammals. This reveals that little was known then of the mechanisms involved in their fertilization, and that a number of the current assumptions were not correct. However, in the early postwar period a number of important observations appeared, not least because of the introduction of the phase contrast microscope and of methods for whole-mount studies of mammalian eggs interacting with sperm. Coincidentally, recognition in 1951 of the need for sperm capacitation made it possible to begin to manipulate mammalian fertilization. At that juncture important contributions came from such as C.R. Austin, R.J. Blandau, A.W.H. Braden, M.C. Chang,, R. Moricard, R.W. Noyes and C. Thibault,.

Given its neophyte status, it was logical that observations on mammalian fertilization should be interpreted at that time very much in light of the principles established for other groups. However, this gave little consideration to unfolding evidence of puzzling new features in the anatomy of mammalian gametes, in the way they interact, and in some aspects of their maturation. By now, our understanding of the situation in reptiles, birds and even monotremes has made it evident that as eutherian and (with some important variants) marsupial mammals evolved, unusual traits appeared de novoin their eggs and sperm. In other words, a layer

Abbreviations used in this paper: Abr, Abbreviation; Abrs, Abbreviations.

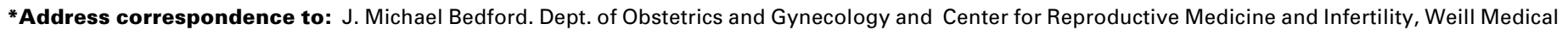
College, Cornell University, Box 30, 1300 York Ave, New York, NY 10021, USA. e-mail: mbedford@med.cornell.edu
}

Published online: 27 June 2008

0214-6282/2008/\$35.00

(C) UBC Press

Printed in Spain 



Fig. 1. Human embryos in culture (A) four days, and (B) five days after fertilization. The four day embryo at the 10 cell stage has not undergone any expansion and the zona (delineated by arrowheads) appears unchanged. At five days the blastocoel is well developed, and expansion of the trophoblast has commenced, thereby stretching the zona and reducing its thickness. The zona becomes even thinner before hatching occurs approximately $36 \mathrm{~h}$ after stage (B). Courtesy of L. Veeck.

of complexity was imposed onto the basic events of conception during the emergence of the Theria, though the little understanding as to why has made it difficult to grasp the ultimate functional significance of its different facets.

What are these novel features? In males they present as: a) a radical design of the sperm head, b) dependence on the epididymis for a post-testicular sperm maturation involving change in various sperm organelles, $c$ ) a regulated sperm storage function created in the cauda epididymidis, d) often a descent of the testis and epididymis to a scrotum, e) a variable set of accessory sex glands. Novelties in the female include: $f$ ) a zona pellucida of unusual thickness and resilience, $g$ ) an often matrix-rich cell mass around it - the cumulus oophorus, $h$ ) a unique selective mode of oviducal sperm transport to the site of fertilization, i) the need for sperm capacitation in the female, j) a unique configuration of gamete fusion via the mid-region of the sperm head - dependent on the stable equatorial segment of the acrosome.


While the main thrust of research on mammalian fertilization now involves molecules that mediate gamete interaction, common models being targeted mutations in the mouse (Okabe and Cummins, 2007), these novel evolutionary features have dogged the mammalian field for years, and not to understand their adaptive significance and how they may relate brings at least the risk of wrong interpretations and time spent investigating blind alleys. Fortunately, the collective evidence now makes it possible to float some explanations. As discussed below, many facets of this complexity appear to be causally linked, one feature having elicited others. The broad picture suggests that a major first 'domino' was the zona pellucida, the formidable character of which determined several new features in the sperm head. However, these features not only imply a novel strategy for the fertilization but together with the reduction in the egg's size would seem to have had profound consequences as well for the way that sperm mature and behave in the male and female

tracts.

In considering their significance, these novel features are considered here primarily in the context of eutherian mammals, but also with 'the fit' of marsupials to these ideas. These views are referenced more fully in Bedford (2004).

\section{Why the novel features of eutherian fertilization?}

During therian evolution the egg lost its genes for yolk production to become very small, as a correlate of the switch to embryonic nutrition via the placenta (Rothchild, 2003). However, this reduction in size was paralleled by a puzzling hypertrophy of the egg's vestment(s). The small marsupial egg is invested solely by a relatively prominent zona pellucida of $2-6 \mu \mathrm{m}$. In eutherian mammals, however, the zona pellucida presents typically as an even thicker $(7-16 \mu \mathrm{m})$ more protease-insensitive elastic coat encased also by a cell mass - the cumulus oophorus. As explained below, the formidable character of the zona in eutherian mammals appears to have evoked new features of sperm head design that reflect a novel strategy for penetrating the zona, and linked to this, for fusion with the egg.

Fig. 2. Novel features of a generalized eutherian sperm head, the acrosome delineated by a hatched line. (1) In sagittal profile, the -S-Sstabilized perforatorium seen in most Eutheria serves to "sharpen" the anterior limit of the reacted sperm head. The inner acrosomal membrane has a relative stability probably lent by a crystal lattice arrangement of its integral proteins. The equatorial segment of the acrosome ensures the maintenance of an unencumbered fusogenic segment of the plasmale$\mathrm{mma}$ at a distance from the sperm head's leading edge. Intermolecular$S$-S- crosslinking of protamine-bound free thiols stiffens the slender sperm nucleus. Most intense in the rostral region of the nucleus, such crosslinking occurs in peri-thecal material as well as the perforatorium. (2) The spatulate form of the sperm head, in flat profile, common in many eutherian spermatozoa. (3) This illustrates the dorso-ventral flattening that allows the sperm head to oscillate laterally during zona penetration. Diagrams $(\mathbf{4}, \mathbf{5})$ illustrate these planes of section $(A$ and $B$ ) in the falciform rodent and the spatulate sperm head, respectively. 


\section{The zona pellucida}

Eutherian eggs do not survive in the Fallopian tube without a normal zona pellucida (Wassarman et al., 1999). This may function variously then to maintain the early blastomeres in apposition, prevent chimera formation between embryos or their sticking to the oviduct wall, perhaps as a barrier to phagocytic cells, and often in avoidance of polyspermy. Thereafter, the eutherian zona is generally retained around the expanding blastocyst until implantation (in animals such as the rabbit, equines, some carnivores, and fur seals, it is substituted or complemented by additional coating material - see Denker, 2000). However, as the blastocyst expands it stretches and so thins the zona pellucida (Fig. 1). The need to withstand such stretching would explain the zona's resilient elasticity and thickness. On the other hand, this means that in contrast to marsupials as well as other vertebrates, eutherian sperm not only must penetrate the cumulus oophorus but an egg coat of striking thickness and elastic resilience. Paradoxically for the concept that eutherian sperm penetration involves zona lysis, that coat is relatively insensitive to serine proteases. When exposed to $0.5-1.0 \%$ trypsin, it requires $\geq$ two minutes to change visibly, compared to the $2-8$ seconds that we have observed must elapse before complete dissolution of the marsupial zona.

Therefore, regardless of whether sperm lysins are involved or not, the character of the eutherian zona points to the need for an unusually physical element in both zona binding and penetration. I suggest that this has determined the behaviour and novel design of the sperm head (Fig. 2), as well as subtle features that lend stability to the reacted acrosome, with the unique mode of gamete fusion as one legacy of this novel design.

\section{The acrosome and zona binding}

In most animals examined closely in this regard, fertilization involves a brief sperm binding, immediate induction of the acrosome reaction $(A R)$ by the egg coat, rapid lytic penetration, then fusion with the oolemma (Fig. 3A). The eutherian situation (Fig. 3B) differs in that vigorous fertilizing sperm need to maintain a relatively prolonged binding to a resilient zona that does not immediately induce the acrosome reaction, and apparently is not later eroded by the products of that reaction. As spermatozoa negotiate a path through the cumulus, the acrosome remains intact or sometimes may begin to react. Then, hyperactivated sperm bind to the zona for a minute and probably often longer before penetrating it. During this step the specificity of binding is believed to depend in part on certain sperm surface sugar residues exposed during capacitation, the tenacity of this interaction enabling hyperactivated sperm (reacting or not) to cling by the peri-acrosomal surface. Aftter the AR, a stable (secondary) binding appears to involve the participation of intra-acrosomal components exposed through fenestrations generated by the AR. Thus, at that point proacrosin may enhance the binding between exposed polysulfate groups on the zona and basic residues of proacrosin/acrosin linked to the acrosomal carapace, via stereochemical interactions involving strong ionic bonds (Gaboriau et al., 2007). Zonadhesins, localised immediately beneath the outer acrosome membrane (OAM) (Bi et al., 2003; Olson et. 2004) also are exposed by the AR.

It is important to stress that reacting eutherian acrosomes seem unusually persistent, certainly as judged by the ease in finding them on the zona in the TEM. I suggest that this persistence reflects a stability brought by the non-soluble acrosomal matrix and, notwithstanding occasional claims to the contrary, is linked to the fact that soluble enzymes released from the acrosome do not erode the zona surface. Absent only at the acrosome margin where the sperm head eventually protrudes through it to penetrate the zona (Olson et al., 2004), this matrix seemingly acts as a scaffold for the vesiculating shroud.

In summary, zona binding in Eutheria represents a disproportionately demanding step in that the vigorous head has to cling while its oscillating movements begin to create a path through the zona matrix, the stable reacted acrosome functioning then as a tether (Fig. 4 - Yanagimachi and Phillips, 1983).

\section{The sperm head}

Whereas the sperm head in most animals is circular in crosssection, that of eutherians is usually flattened in one plane, allowing it to oscillate in that plane during zona penetration. Second, an unusual -S-S- dependent keratinoid quality serves to rigidify or stiffen the head (Fig. 2). These features alone imply a design for shearing thrust, but the conclusion that a physical element in penetration has determined the design of the sperm head finds support in two other features - the stable crystallatticed inner acrosomal membrane (IAM), and, linked to it, the unreactive equatorial segment of the acrosome. Whether or not some form of lysis is involved as well (see below), the likelihood that zona penetration involves shear forces created by the rapidly oscillating head would account for the characteristic stability of the IAM, which bears the brunt of that interaction. At the same time, however, this would preclude the IAM's traditional role as a fusogenic membrane. An enigma in the early days of sperm anatomy research, the equatorial segment can be seen now as an

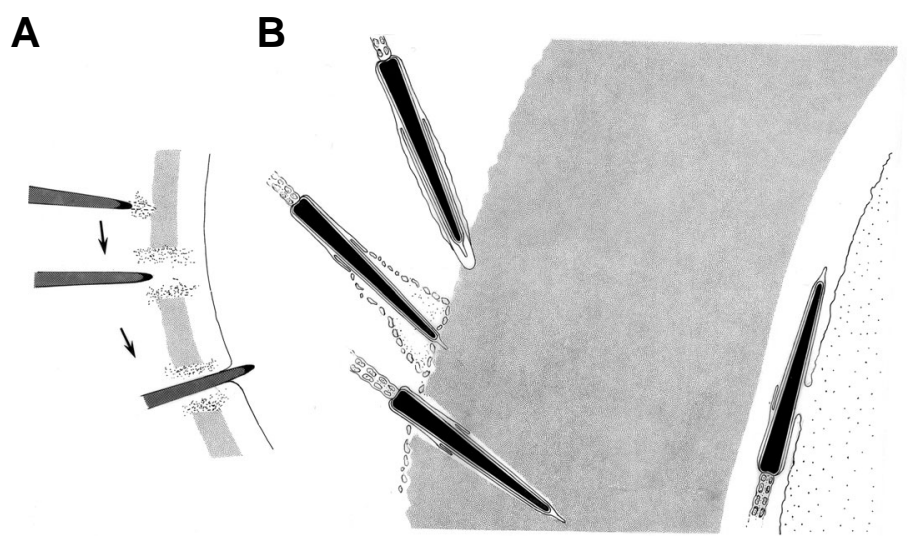

Fig. 3. Sperm penetration in many sub-therian animals (A), compared to that in eutherian mammals (B). In many sub-therians, sperm attachment to the egg surface triggers an immediate reaction of the acrosome, the contents of which lyse a penetration path in a flimsy egg coat, followed rapidly by fusion between the apex of the inner acrosome membrane and the oolemma. In contrast, the eutherian acrosome often remains intact for a period after binding to zona, and when reacted remains as a visible entity that tethers the sperm head until it can intrude via its oscillations into the matrix, leaving the vesiculating acrosomal shroud at the zona surface. In further contrast, eutherian gamete fusion occurs not via the relatively stable inner acrosome membrane but by way of the plasmalemma segment overlying the persistent equatorial segment of the acrosome. 
adaptation that operates to preserve a fusogenic membrane segment in a location removed from the sperm head's leading edge.

\section{Zona penetration: lysis and or physical thrust?}

As noted, the formidable character of the eutherian egg coat and the several novel features of the sperm head carry the implication that significant physical force is involved in penetration of the eutherian zona. Nonetheless, the belief holds sway still that this step depends on the cooperation of one or more acrosomal enzymes acting as egg coat lysins, as they do in many other groups. This expectation for eutherian mammals seemed fulfilled many years ago by observations: a) that acrosomal extracts could eventually disrupt the rabbit zona (Srivastava, Adams and Hartree, $1965)$, b) that such extracts always contain acrosin (Zaneveld and De Jonge, 1991) and c) that fertilization in vitrowas blocked in the presence of protease inhibitors (McRorie and Williams, 1974). However, while it is hard to abandon the long-held concept that penetration of the eutherian zona is mediated by acrosomal lysins, this now has many holes.

First, TEM studies in the 1960's revealed that the soluble content of the eutherian acrosome disperses before zona penetration - a finding that does not mesh with the lysin concept. I did then propose that lysis could depend on enzyme residue(s) bound to the IAM, but this does not seem to hold water for several reasons. Not only has the notion of acrosin binding to the IAM since been rejected on the basis of its molecular structure (Klemm et al., 1991), but immunocytochemical studies of bull, boar and rabbit sperm by Flechon and colleagues (e.g. Shams-Borhan, Huneau and Flechon, 1979; Kopecny and Flechon 1987) detected no acrosin on the IAM of the reacted head. Furthermore, mutant mouse sperm lacking acrosin fertilize normally if more slowly (Baba et al., 1994) - the latter perhaps due to a delay in completing the AR in the absence of acrosin. The case for a serine protease as such a lysin was weakened also by finding that a significant increase in the trypsin-resistance of the (rabbit) zona had no measurable effect on penetration as judged by sperm numbers reaching the perivitelline space within a given time (Bedford and Cross, 1978). Finally, the early conclusion coming from fertilization-suppression by protease inhibitors is undermined by the fact that these also prevent completion of the AR (Meizel, 1984; Llanos et al., 1993).

The possibility that eutherian sperm may penetrate the zona without the cooperation of acrosomal lysins is consistent with deviant patterns in such as shrews, Asian bandicoot rats, and the American opossum. In the case of shrews studied carefully, the cumulus stimulates the AR such that the acrosome and its content are always shed well before reaching a conventional zona pellucida (Bedford, Mock and Goodman, 2004). In Bandicota indica, the sperm head is circular in cross-section and so cannot oscillate, and sports a bulky rostral acrosome lacking an equatorial segment (Breed, 1993). Coincidentally, its zona pellucida is only $4 \mu \mathrm{m}$ thick (W.G. Breed-personal communication) and dissolves in $1 \%$ trypsin in ca. 20 seconds (JMB personal observation), compared to $\geq 2 \mathrm{~min}$. in most Eutheria. This rare example among Eutheria implies penetration via zona lysis in $B$. indica. Finally, it seems paradoxical for the zona lysin concept that the acrosome of the marsupial Didelphis virginiana contains higher concentrations of acrosin and several glycosidases than that of the rabbit, notwithstanding a much thinner and highly protease-sensitive zona (Rodger and Young, 1982). This implies that there has been no parallel selection for acrosomal lysins as a correlate of the increased prominence of the eutherian zona.

\section{Summary}

Substituting the traditional view of a serine protease lysin in Eutheria - the evidence for which is now weak - it has recently been proposed that a proteosomic hydrolase of the (pig) sperm head operates as such (Yi et al., 2007). Nonetheless, regardless of whether or not some form of lysin proves to be involved, the design of both gametes points to the sperm binding and zona penetration steps in Eutheria as being unusually physical events. I infer from this that the formidable character of the eutherian zona pellucida has elicited several novel features in the sperm head. These include its shape and rigidity, the relative stability of the reacted acrosome and IAM, and the equatorial segment that maintains an alternative site of fusion (Fig. 1).

\section{Indirect origins of novel features}

The broader picture suggests that the character of the eutherian zona pellucida has been responsible ultimately also for other gamete-related novelties. This egg coat may have determined not only an unusual sperm head design and penetration mode in Eutheria, but indirectly a greater complexity of epididymal function - reflected in both the pattern of sperm maturation, and, as a consequence of that, regulated sperm storage in the cauda region. In turn, the latter function appears to underlie the need for sperm capacitation, which I suggest represents a 'reversal' of a stable state that permits sperm to remain viable during storage in the cauda. In addition, the common exteriorization of the cauda to a cooler site not only appears to favour its capacity for sperm storage but to have been a determinant of the scrotal state.

\section{Sperm maturation in the epididymis}

Sperm pass through the Wolffian duct of the rooster in only 24$48 \mathrm{hrs}$, but though coated there by a secretory protein, maturation of their fertilizing ability seems to involve only the capacity for motility. Nor is this necessarily dependent on the Wolffian duct since a few sperm collected directly from the rooster testis are able to fertilize. By contrast, the maturation of eutherian spermatozoa is more prolonged, has come to depend on specific epididymal factors, and broadly involves four elements - the -S-S- related structural quality of the sperm head and tail, acrosome organization and morphology, sperm motility, and not least the state of the plasmalemma. While this trend to complexity is hard to explain fully, the evidence now suggests again that some aspects relate to challenges posed by the zona pellucida.

Sperm structure: The structural changes of maturation involve crosslinking of protein-bound free-SH in the sperm tail and head. Keratinoid tail fibers are not uncommon in other vertebrates, and presumably bear on the form of the beat. However, for reasons that are unclear, in eutherian and marsupial sperm alone the mitochondrial shell also is stabilized by disulphide bonds - this apparently mediated by a selenoprotein PHGPx (Ursini et al., 1999). The significance of -S-S- crosslinking of the unusual cysteine-rich protamine and perinuclear material of the immature eutherian sperm head seems easier to understand. Absent or 
largely so from other vertebrates including marsupials, such crosslinking within the nucleus during epididymal passage has been suggested to protect its DNA, and indeed it does allow the sperm genome to better survive freeze-drying. Yet, the sperm genome is certainly exposed to similar or greater 'risks' in other amniotes whose sperm nucleus lacks such crosslinking. The occasional TEM view of a sperm head buckled within the zona pellucida, our experimental observation that -S-S- bonds stiffen the sperm head, and the fact that among amniotes the keratinoid nucleus is a feature of eutherian sperm only, together suggest that it represents an adaptation which helps the sperm head to withstand forces involved in penetration of the formidable eutherian zona pellucida.

Acrosome maturation: It is hard to be sure of the significance of the visible changes in acrosome morphology during epididymal passage (Yoshinaga and Toshimori, 2003; Olsen, Winfrey and Nagdas, 2003), particularly since these are not seen in all mammals. However, visible or not, epididymal changes in the acrosome may represent a further organization of internal elements such as the matrix, proacrosin and zonadhesins that help it to persist while tethering the vigorous sperm head to the eutherian egg coat.

Sperm motility: The fact that sperm generally develop the potential for optimal motility after leaving the testis in vertebrates with internal fertilization may reflect the fact that, in addition to the usual oxidative phosphorylation, they have developed a capacity for glycolysis in face of a more prolonged life in the female tract. However, in contrast to those of the rooster at least, eutherian spermatozoa cannot develop the potential for optimal motility if withheld in the testis, and to do so require some exposure to the upper epididymis. In a still very incomplete picture, increased cAMP levels seem important in this regard (Smith et al., 1996), a point consistent with the observation that immature epididymal spermatozoa permeabilized with Triton X-100 then move actively on exposure to cAMP or ATP (Mohri and Yanagimachi, 1980). This last observation accords also with other evidence that a key


Fig. 4. Scanning electron micrographs of spermatozoa progressively entering the zona surface in eggs recovered from a mated hamster approximately $3 \mathbf{h}$ after ovulation. As sperm negotiate a path into the matrix they remain tethered to the zona by the acrosomal shroud (arrowheads). Courtesy of R. Yanagimachi and D.M. Phillips. element for maturation of the motility function is an epididymisdependent modification of the sperm plasmalemma.

The sperm plasmalemma: Epididymal change in the sperm plasmalemma appears to be important not only for sperm motility, but for sperm binding to the zona and for storage in the cauda epididymidis. In the few representative reptiles and birds studied, the sperm surface binds protein secreted by the male duct system, as it does in mammals. This protein acquisition may possibly help sperm to survive the rigours of the female tract, but in mammals epididymal change in the sperm surface has long been linked to other functions, including the ability to fertilize. Moreover, in contrast to the few other amniotes studied, sperm surface change in therian mammals involves some modification of glycosyl moieties that probably are involved in zona binding. As observed in the rabbit and mouse, epididymal change in the sperm plasmalemma is reflected most obviously in an increasing tendency for sperm head autoagglutination, or for non-specific adherence to the zona surface (Bedford, 1967; Saling, 1982). However, my early observation that this ability cannot be achieved in the 'initial' segment of the rabbit epididymis, points to the existence of a specific regionality in regard to the factors that bring about sperm surface maturation. The picture now suggests that, as well as molecules acquired by the surface domain of the tail, one important aspect reflects some modification of peri-acrosomal glycosylated elements involved in specific primary binding to a resilient zona pellucida. In the case of human spermatozoa, that role may involve the epididymal secretory glycoprotein $\mathrm{P} 34 \mathrm{H}$ (Boué and Sullivan, 1996).

In fact, however, the changes in the sperm surface are more complicated in several respects. First, the strict specificity of zona binding at fertilization may be expressed only after sperm are capacitated. Epididymal sperm surface modifications can also involve at least membrane cholesterol, phospholipid, proteins, glycosylated and sulfated proteins, and peptides (Jones, 1998; Flesch and Gadella, 2000), with some molecular variation according to species (Cross, 1998). In addition, there is evidence that an epididymal protein of the CRISP family facilitates the interaction between the equatorial region and the oolemma that precedes gamete fusion (Ellerman et al., 2006). Furthermore, certain membrane components first expressed in the mid-corpus region of the epididymis constitute receptors for others that nowfertile spermatozoa acquire within the cauda (Rifkin and Olson, 1985; Yeung et al., 1997; Derr et al., 2001). Thus, changes undergone in the sperm plasmalemma apparently involve not only the ability to fertilize but finally sperm storage in the cauda region as well.

\section{Sperm storage in the cauda epididymidis}

With the exception of some passerine birds, only in therian mammals is a portion of the Wolffian duct differentiated as a specific storage site regulated by testosterone and in most cases by the lower temperature of the scrotum. The cauda is characterized 
by a capacity to store some 5 - 10 days testis sperm production, by a contractile quiescence that favors sperm retention in its wide convoluted duct, and by a local environment that prolongs the life of mature sperm. In the case of the rabbit I have determined that they remain in an optimal state in the cauda for several days longer than the natural mean time-span (ca. 9 days) of their residence there. But why did such a special sperm storage function evolve, and why should mature sperm need the environment of the cauda in order to survive as viable cells?

The cauda may well have evolved because the Theria produce comparatively low numbers of more complex spermatozoa that undergo a complex maturation in the epididymis marked by a slow rate of passage through it. The potential end-result of this is a limited ability to immediately replace the population being ejaculated, and the benefits of regulated storage become evident in comparing the rat v. the quail (Clulow and Jones, 1982) or the rabbit v. the rooster in this respect. Such birds have larger testes/ gm of body mass, and a more rapid spermatogenesis, posttesticular maturation and sperm transport through the male duct. However, the organization of the cauda allows mammals to produce repetitive ejaculates over one limited time period, the total sperm number thereby being broadly comparable to that which birds can produce over any brief period.

Once they gain the ability to fertilize, spermatozoa withheld in any upper region of the epididymis remain viable thereafter for no more than about 3+/- days. But why mature spermatozoa should be so vulnerable, and how the milieu in the normal cauda prolongs their functional life, is not clear. A key may be the fact that, in such as the rat or hamster, different domains of the plasmalemma in already-fertile sperm entering the upper cauda then acquire a species-variable mix sterols and of secretory macromolecules that presumably facilitate storage. In order to fertilize, however, sperm may need to revert from a stable state compatible with storage to a responsive state appropriate to the membranerelated events of fertilization - a change embodied in the phenomenon of capacitation.

\section{Sperm capacitation}

In contrast to the immediacy of fertilization after eggs are exposed to sperm in other groups, spermatozoa of eutherian mammals finally develop the capacity to fertilize only over a period of some hours in the female tract. It seems notable that this (and evolution of the scrotal state - see below) parallels the operation of a regulated sperm storage in the cauda epididymidis. For, as implied above, it seems likely that capacitation is a legacy of that storage function, and represents a necessary transformation from a stable to a responsive state. In Eutheria, this change in the sperm plasmalemma is translated ultimately to a), the ability of the acrosome to react in response to an appropriate stimulus and, b) a whiplash-like hyperactivated motility, usually stimulated by the environment of the Fallopian tube. While the functional significance of the latter aspect has remained in some doubt, we observed that sperm did not hyperactivate in vivo as a function of capacitation in a small marsupial (Bedford and Breed, 1994). This supports one possibility that the shift to hyperactivated motility represents yet another accommodation to the challenge of the eutherian zona.

Capacitation is a non-specific phenomenon that can be achieved in vitro with varying ease according to species. Nonetheless, the molecular nature of the capacitated-related change(s) in the sperm plasma membrane has proven hard to pin down, and probably differs somewhat among different mammals. There is an increasing consensus, however, that in some species including man capacitation involves a loss or redistribution over both the sperm head and tail surfaces of molecules acquired in the lower corpus/upper cauda regions of the epididymis that may act to prolong the life of sperm there - specifically sperm membrane cholesterol (Cross, 1998; Osheroff et al., 1999), and of certain glycoproteins (Yeung et al., 2000). In general accord with this concept, mature porcine spermatozoa from the upper epididymis developed the ability to fertilize in the oviduct sooner than those from the lower cauda (Hunter, Holtz and Henfrey, 1976), whereas capacitation was prolonged if they were first exposed to cauda secretions (Hunter, Holtz and Hermann, 1978). Similarly, capacitation occurs sooner in hamster spermatozoa from a cauda epididymidis suppressed by body temperature (Bedford and Yanagimachi, 1991), which reduces the cauda's production of certain proteins, including the sperm-coating glycopeptide, CD52. (Derr et al., 2001)

\section{The scrotum}

Based on the collapse of spermatogenesis at body temperature in scrotal mammals, it has long been supposed that a cooler temperature serves some special aspect of testis function. How-

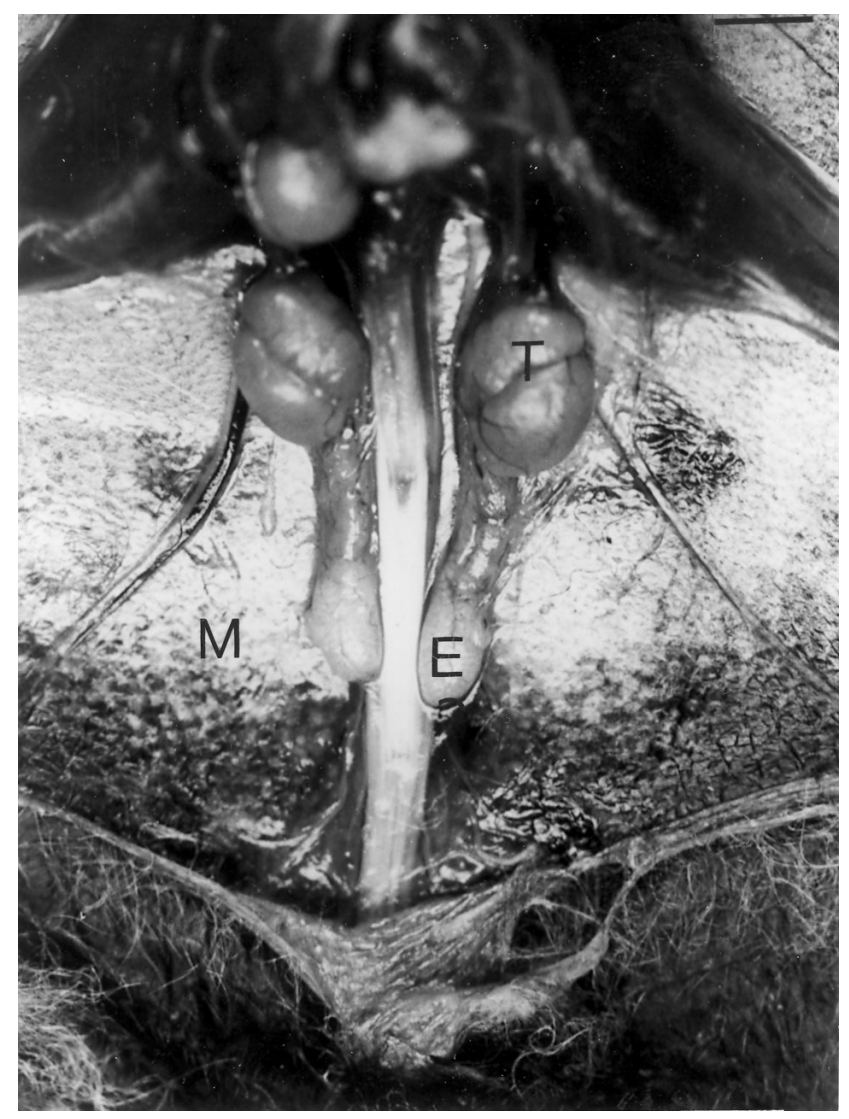

Fig. 5. Inguinal region of the bat Miniopterus schreibersiifrom which the skin has been removed. The support of the interfemoral membrane (M) slung between the back legs allows the cauda epididymidis (E) to protrude far beyond the still-inguinal testis (T). 
ever, this traditional view has several weaknesses, and convincing explanations for evolution of the scrotum have remained elusive. Although it has been argued that homeothermy was responsible for the scrotal state (Werdelin and Nilsonne, 1999), among other things this does not tally with the testocondid status of birds. The idea that testis cooling may reduce sperm mutations was aired on the basis that recombinant repair by meiotic crossing-over is precluded by the heterogametic $(X Y)$ state of male mammals, unlike that of homogametic [ZZ] male birds (Short, 1997). Yet, not only does the testicondid situation occur without genetic penalty in some male mammals, but it is now evident that gene conversions occur between palindromic arms of the eutherian $Y$ chromosome (Rozen et al., 2003). Moreover, in such as the cane rat which lives in the hot Llanos of Venezuela, the scrotal testis has adapted to an ambient temperature equal to that of the abdomen, as it may have in some other species living in that environment (Bronson and Heideman, 1993). Ultimately, however, it is the overlap of the ranges of body temperature among scrotal, quasi-scrotal and ascrotal species (Carrick and Setchell, 1977) which vitiates the concept of the scrotum as a means of shielding the testis from body temperatures. Such examples cast doubt on the argument that spermatogenesis in therian mammals is fundamentally incompatible with temperatures at or close to that of the body.

In considering the significance of the scrotum, it is important to recall that there is no regulated sperm storage region in the Wolffian duct of most birds, nor in other sub-mammalian vertebrates studied in this respect. This distinction seems important in light of three-pronged evidence for a contrarian view that evolution of the scrotum may have been driven by some advantage a lower temperature brings for the sperm storage function of the cauda epididymidis. First, the exposed disposition of the cauda is orchestrated by the curious u-shape course traced by the epididymis and vas deferens, which serves to situate it in a cool spot, either sub-integumental or truly scrotal. Second, whether the testis is inguinal or scrotal, the cauda epididymidis usually projects beyond it such that in the rat and degu, for instance, the cauda is about $4^{\circ} \mathrm{C}$ cooler than the testis. Extremes in this regard are seen in some bats (e.g Miniopterus schreibersii) where the cauda supported by an interfemoral membrane projects far beyond the inguinal testis (Fig. 5). Third, among representative species, scrotal features clearly optimise cooling of the cauda rather than the testis. These features include a discrete peri-caudal baldness (Fig. 6 - white-tailed rat, bushbaby, laboratory rat, Clun Forest ram) (Bedford, 1978; Contreras and Rosenmann, 1982), as well as pigmentation of that pericaudal region (bushbuck, red fox), its exaggerated dartos muscle activity, and insulation of the cooler cauda from the warmer testis by a fat pad (rat, degu). Whereas these features all favour cooling of the cauda, in no case does the form of the scrotum or the disposition of its contents seem directed to preferential cooling of the testis.

Although the collapse of spermatogenesis at body temperature in scrotal species is visibly dramatic, the scrotal cauda proves to be just as vulnerable. Although body temperature does not suppress sperm maturation in the epididymis, it dramatically curtails the cauda's storage capacity and its support of sperm viability. These effects are reflected in a reduced diameter and length (and so carrying capacity) of that duct segment, in ionic exchange across the epithelium, in the cauda's pattern of protein

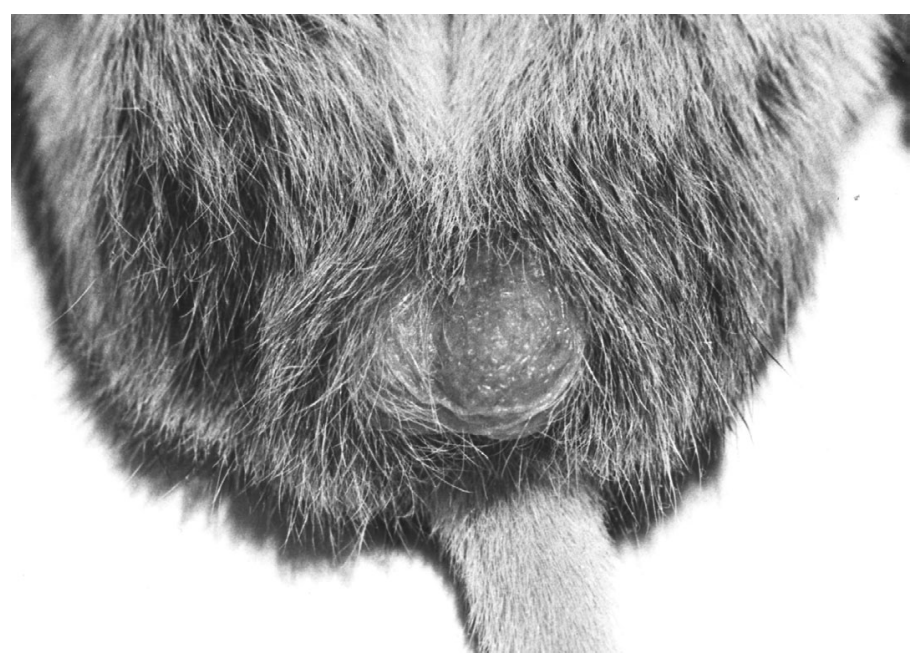

Fig. 6. The scrotum of the white-tailed rat, Mystromys albicaudatus. This illustrates the discrete bald region that covers the cauda epididymidis, in contrast to the heavy fur that overlies both testes. Such a differentiation of the scrotal pelage is seen in a variety of different eutherian genera.

secretion, and in at least one gene normally expressed locally in the cauda.

These indications that the scrotum is really organized to cool the cauda epididymidis raise questions not only as to what may have driven this function, but why the testes descend, and why they are sensitive to body temperature? I have suggested that externalization of the testis in the mammalian progenitors enabled the associated cauda to "ride" to a cooler location. As mentioned, an unusual alternative is illustrated in the bat, M. schreibersii, whose cauda is suspended within the interfemoral membrane enabling it to project far beyond the still-inguinal testis (Fig. 5). Second, since there is evidently no fundamental incompatibility between body temperature and spermatogenesis, as evidenced by the mammals with abdominal or pelvic testes, the common sensitivity of the descended testis may simply reflect its secondary adaptation to the lower temperature of the scrotum. There are several examples of organs adapting to lower temperatures, and in the case of the scrotal testis its sensitivity may just reflect an adaptation of key metabolic pathways. For instance, the kinetics of the rat testis isoform, phosphofructokinase, are optimal at $32^{\circ} \mathrm{C}$ rather than $37^{\circ} \mathrm{C}$ (Ewing and Schanbacher, 1970).

Finally, while various colleagues and I have shown that elevation of the cauda's normal temperature to that of the abdomen modifies the intra-tubal milieu and reduces its capacity, it remains to be explained why a lower temperature of a few degrees should favour and also co-regulate sperm storage? And why is the eutherian testis not always externalized to a similar degree if this optimizes sperm storage? In statistically assessing a wide range of mammals, Freeman (1990) concluded that internal testes tend to be larger relative to body size, and that relative testis size declines according to the degree of descent. Since sperm production largely relates to the size of the testis (Moller, 1989; Short, 1997), the degree to which it is externalized could therefore represent a trade-off between sperm production and storage. In other words, optimizing sperm storage may enable a lower sperm production by the testis without compromising male 
fecundity. In that regard, storage some degrees below body temperature in the coiled lower Wolffian duct of some passerine birds within a scrotum-like seminal glomus, favours ejaculation of larger numbers of spermatozoa - a possible advantage in a situation of sperm competition (Birkhead, 1998).

\section{Novel aspects in the oviduct}

The pre-fertilization phase in the eutherian oviduct is characterized by two further novelties - fine control of sperm transport to the ampulla, and the cumulus oophorus. Both would seem to be linked ultimately to the small size of the egg.

\section{Oviducal sperm transport}

In many sub-therian vertebrates with internal fertilization, relatively large yolky eggs entering the oviduct are directly exposed to spermatozoa released coincidentally from storage crypts. This exposure generally results in a physiological polyspermy, in which only a single sperm head becomes a male pronucleus. By contrast, regardless of wide species variation in sperm numbers entering the uterus, the eutherian oviduct is organized to ensure that very few sperm inhabit the ampulla at the time of fertilization, and in some small mammals then they hardly equal the number of eggs. Parenthetically, therefore, one should be wary of the concept that there is a 'race' to reach unfertilized eggs as a function of the sperm's velocity, and of media images showing many sperm supposedly competing for an unfertilized egg. This parsimonious end-result is established by first withholding sperm that pass through the utero-tubal junction (hundreds or thousands according to species) in a limited segment of the isthmus. Their confinement to the isthmus is achieved via sperm adherence to the tubal epithelium mediated by glycosylated moieties expressed at the peri-acrosomal surface in an environment often rich in mucus. The release of a select few from this isthmic storage region is possibly aided by the disruptive agency of hyperactivated motility (Ho and Suarez, 2001), it is timed to coincide with ovulation and is controlled by endocrine signals from ovulating follicles of the ipsilateral ovary (Hunter, 1996).

But why is the fertilizing eutherian sperm population regulated in this novel way? All the indications point to it as a way of avoiding polyspermy (Hunter, 1996) which is lethal for the therian embryo and is a common sequela of an increased sperm number naturally reaching the ampulla. For instance, there is evidence that significantly more sperm reach the ampulla in small rodents after both delayed mating or multiple matings, both of which result in a greater incidence of polyspermy. Likewise, in pigs removal of the isthmus resulted in many more ampullary sperm, and coincidentally in $34 \%$ of eggs becoming polyspermic (Hunter and Léglise, 1971). Thus, the presence of more than a minimal number of spermatozoa during eutherian fertilization increases embryonic failure.

Whether this picture closely describes the situation in most mammals is not certain, and in larger animals greater numbers of spermatozoa may reach the fertilization site. Moreover, while sperm adherence to the isthmic epithelium is the most common, it is not the only strategy used to regulate sperm transport to the fertilization site in Eutheria. In dogs, spermatozoa seem to be first withheld for several days in uterine crypts, and in some hibernating bats the control point is the uterotubal junction. Particularly striking, shrews (and on the basis of their oviduct anatomy moles) achieve a comparable fine regulation of numbers at the fertilization site by sequestering sperm in multiple crypts located in different regions of the oviduct according to species. During the preovulatory phase, such crypts entrap/some 500-1500 freely moving sperm per tube, and then at ovulation release about 10 or fewer to the immediate vicinity of the eggs lying in the infundibulum (Bedford, Mock and Goodman, 2004). Given the view that shrews most closely resemble the small mammalian progenitors, this raises a question as to whether this equally selective but very different mode may have been the norm in the early evolutionary period.

\section{The cumulus oophorus}

The cumulus oophorus is another novel eutherian element that bears directly on the events of fertilization (and that has a special character and function in shrews at least). Present in Eutheria alone, the cumulus oophorus comprises a mass of what were follicular cells retained around the ovulated egg, often embedded in a proteoglycan matrix secreted soon before ovulation. In polyovular animals, several cumuli generally coalesce in the oviduct to form one clump, and very often the cumulus persists during and after fertilization. With the exception of shrews and probably a few other genera, cumulus-free eggs can be fertilized in vivoand in vitro. Why then does the cumulus remain in Eutheria for a species-variable period after ovulation, and why do its cells secrete a matrix in the hours before ovulation?

There have been various suggestions as to the role of the cumulus, and indeed this may well now differ from group to group. However, although the cumulus persists for only a few hours at best in some ungulates, I believe that the overall picture favours the early suggestion (Chang and Pincus, 1951; Austin and Braden, 1952) that the cumulus often operates to enlarge the egg-associated target for the few potentially fertilizing sperm that reach the spacious ampulla ( $\mathrm{L}$. swollen vessel), thereby promoting the chance of fertilization. In accord with this, not only does the eutherian ampulla usually dwarf the eggs, but in such as the rat we have seen that the cumulus sequesters virtually all the ampullary sperm during the peri-fertilization period. Similarly, cumulus-invested rabbit eggs are fertilized in the ampulla sooner than their naked counterparts.

Notwithstanding several roles proposed for the cumulus matrix (e.g. as a facilitator of ovulation or cumulus penetration, or as a suppressor of follicular vascularization), a comparative glance at eutherian oviduct dimensions suggests that this matrix is secreted consistently in species with a relatively spacious or arborized ampulla, and that it furthers the role of the cumulus as a sperm target or sequestering device for the very few sperm arriving in a space much larger than the egg(s). In accord with this, when the upper oviduct diameter is minimal (e.g. in some small bats, in canidae and and in insectivora) the cumulus is virtually matrix-free.

Finally, although the cumulus may often promote the meeting of sperm and eggs, nevertheless it is essential for fertilization in a few cases that include the Chinese hamster and shrews. In shrews at least, this reflects the fact that the cumulus induces the $A R$, with the zona pellucida apparently unable to do this (see Bedford, Mock and Goodman, 2004). Therefore, the common view that the ancestral mammals resembled present-day shrews 
again raises the question as to whether the AR-inducing function of the cumulus was typical for the eutherian progenitors, or represents an apomorphy peculiar at least to present-day shrews and probably a few other eutherians as well.

\section{The bearing of marsupial patterns}

Since marsupials arose from a common therian ancestor, and also present an interesting mix of sometimes different gameterelated novelties, they provide something of a sounding board for the present interpretations in regard to eutherian mammals. A review of the more limited evidence for the events leading to conception in marsupials reveals no obvious discord with the interpretations made here for eutherian mammals. To consider first the zona pellucida, while much less is known about its interaction with sperm, the marsupial zona appears to be something of a halfway-house between that of eutherians and that in many other groups. Although relatively thick at about 2 - $6 \mu \mathrm{m}$, and constituted by the same glycoproteins (Breed et al., 2002), the marsupial zona has no structural memory and $0.1 \%$ trypsin dissolves it completely in 2-8 seconds - far faster than the $\geq 2$ minutes required for the eutherian zona. Its role is also very different in some respects in that it is invested soon after fertilization by mucoid and then a persistent elastic shell laid down by 24 - 36 hours as the egg passes through the uterotubal junction (Roberts, Breed and Mayrhofer, 1994). Soon thereafter the zona erodes and essentially disappears before expansion of the developing conceptus (Selwood, 2000).

However, since the marsupial zona is more substantial than the egg coat in most metazoa, it is interesting that the sperm head displays a unique design that may represent an adaptation to the zona's character. While minor differences occur between the paired sperm of the New World genera and the single spermatozoa of Australian marsupials, the marsupial sperm head has none of the eutherian features I associate here with physical stress. Rather, its unusual configuration enables the sperm head to

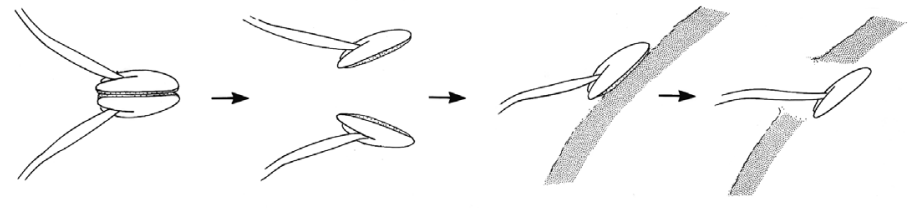

A

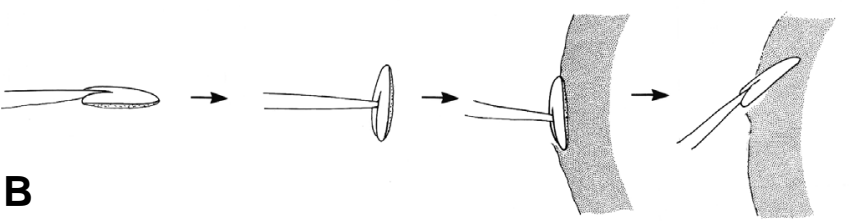

Fig. 7. The form of spermatozoa before and during zona penetration in (A) an American didelphid marsupial, and (B) an Australian dasyurid marsupial. Didep/phis spermatozoa pair via the acrosomal face while passing through the epididymis, unpair in the Fallopian tube, and appear to penetrate via the broad face of the acrosome, leaving a relatively wide gap in the zona. In the dasyurid Sminthopsis crassicaudata, the streamlined form of ejaculated spermatozoa is transformed in the oviduct to a potential T-shape by rotation of the head on the capitulum of the tail. After binding in a T mode to the thicker zona, it reverts to a more streamline shape in the penetration phase. present the whole face of the acrosome as it binds to the zona (Fig. 7), probably thereby maximizing the action of its content against a protease-sensitive if more prominent zona. Therefore, it is interesting that in a model such as the dunnart, TEM images revealed that penetrating sperm may carry vestiges of acrosome content juxtaposed to dissociating matrix (Breed, 1994), actually suggesting the operation of zona lysis.

In regard to the marupial epididymis, our observations have indicated that other than -S-S- crosslinking of the sperm nucleus the pattern of sperm maturation is broadly similar to that in eutherians, and morphologically sometimes more exaggerated. However, while marsupial sperm can certainly be found adhering to the zona pellucida, too little is known of the details to be able to project with any certainty the bearing of sperm/egg interaction on the evolution of the marsupial epididymal maturation process. On the other hand, the features of that maturation are together consistent with the idea invoked for the eutherian situation that this pattern determined development of the regulated sperm storage in the marsupial cauda epididymidis. In turn, the presence of this latter function (Chaturapanich et al., 1992) accords with our evidence that marsupial sperm require capacitation in order to undergo the acrosome reaction, and with evolution of the scrotal state. However, because the scrotum is an androgen-independent structure that lies anterior to the penis (Renfree et al., 1995), it may have evolved independently in the marsupial line.

As noted earlier, the observation that sperm of the marsupial dunnart are not hyperacivated at the fertilization site lends some weight to the possibility that this motility shift in eutherian sperm is indeed one legacy of the character of the eutherian zona The fact that the marsupial egg is devoid of cumulus oophorus appears consistent with the notion that this cell mass often serves in Eutheria to enhance the size of the egg-related target, and sequester sperm at the spacious fertilization site. For the snug fit of the naked marsupial eggs to the narrow dimensions of the upper oviduct means that they inevitably meet upwardly migrating sperm, many becoming enmeshed within the egg's mucoid acquired soon after fertilization. The mode of sperm behaviour in the marsupial oviduct is more difficult to understand, however, for three reasons. Where sperm are stored first in oviduct crypts in both dasyurid and didelphid marsupials, that pattern seems more akin to events seen in some birds and reptiles. Second, such a crypt-based system may not even operate in macropod marsupials. Finally, while the risk of polyspermy may have been a determining factor in the eutherian oviduct, too little is known of the means by which marsupial eggs avoid this lethal state to understand why sperm are disposed so differently as compared to the pattern common to many Eutheria..

\section{Conclusions}

The eggs and sperm of eutherian mammals display novel features whose adaptive significance has been difficult to decipher. Although it would seem a stretch at first glance, it seems quite possible now that these gamete-related novelties owe their genesis, directly or indirectly, to evolutionary changes in the egg ordained by blastocyst development and so perhaps events related to nidation (Fig. 8). A major determinant would seem to have been a thick zona pellucida that can stretch yet persist around an expanding blastocyst, another determinant being the 
small yolkless state of the egg.

A hypertrophic resilience of the eutherian zona pellucida appears to have evoked several novel sperm head features related to its penetration. The unique design and oscillatory behaviour of the sperm head lend themselves to an unusual strategy of physical thrust, and the bulk of current evidence now speaks against the original belief that zona penetration is facilitated by acrosin acting as a zona lysin. Regardless of recent reports that other enzymes could have such a role, the overall picture does points to the presence of a truly physical element in penetration of the eutherian egg coat. This includes a relatively prolonged and tenacious sperm head binding to the resistant zona surface, and a persistence of the reacted acrosomal shroud as a tether until the sperm head begins to penetrate the zona matrix by way of oscillating thrust. Coincidentally, the inner acrosomal membrane which bears the brunt of that interaction displays an unusual stability incompatible with fusion. However, development of the inert equatorial segment of the acrosome has allowed the maintenance of an alternative segment of fusogenic membrane overlying it. This arrangement has clearly been responsible for the configuration of the gamete fusion step unique to eutherian mammals.

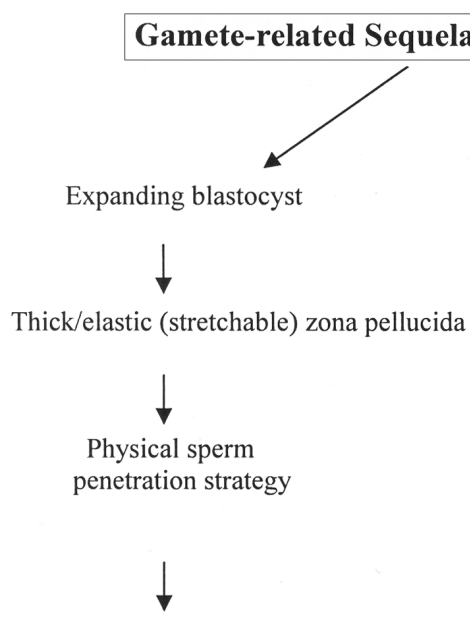

Novel sperm head anatomy

a) Surface binding properties

b) Stability of reacted acrosome

c) flat profile

d) -S-S- dependent rigidity

e) resilient IAM

f) eq. segment of the acrosome



Fig. 8. Reproductive biology dominos. This schematic sequence attempts to convey the relationships whereby one new development in the reproductive biology of eutherian mammals appears, in 'domino' fashion, to have been the stimulus for the development of others.
It is possible to argue also that the eutherian zona pellucida has elicited further novelties related to sperm maturation in the epididymis, and to other aspects of male tract function. Although the significance of some changes that sperm undergo in the epididymis remains difficult to fathom, -S-S- crosslinking that serves to stiffen the sperm head is a likely adaptation to the resilient character of the zona. On the other hand, it is harder to be sure of the significance of changes in the acrosome's content and in some cases its morphology during epididymal passage, other than to speculate that this may again relate ultimately to the resilient state of the insoluble zona matrix and so to the reacted acrosome's role as a tether during secondary binding to the zona. In regard to sperm motility, experiments with permeabilized spermatozoa point to maturation of this as depending in part at least on some modification of the sperm tail plasmalemma. On the other hand, why this aspect of sperm maturation should be linked necessarily to the epididymal environment in eutherian mammals is hard to divine. Finally, in regard to the sperm cell membrane, though the molecules involved in its changing properties during epididymal maturation probably differ somewhat according to species, the state of this membrane also appears to have an important bearing not only on primary binding to the zona, but also on the ability of sperm to be stored in the cauda epididymidis.

The sperm storage function of the cauda seems likely to have arisen because, compared to that in the rooster for example, sperm maturation in the eutherian epididymis is more complex and relatively prolonged, and sperm passage to a point from which they can be ejaculated is correspondingly slow. These timings translate to a limited potential for replacement of mature sperm after ejaculation. However, that problem is mitigated by the organization of the temperature- and or androgen-regulated sperm storage function of the cauda epididymidis, which often allows for the delivery of a series of fertile ejaculates within a short period. Although the factors that allow such storage have yet to be defined, one key element for cauda sperm would seem to be the late surface change brought by certain secretory proteins. When ejaculated, however, sperm apparently must revert from a state that favours storage to one appropriate to fertilization - a transition manifested as capacitation. Finally, a variety of evidence points to the function of the cauda as a determinant also of the scrotal state, though it remains to be explained why a lower temperature of a few degrees can co-regulate the cauda's storage function, and what is the advantage that comes from cooling it.

In considering two final novelties, finetuning of sperm transport in the oviduct and the cumulus oophorus, it can be argued that an important determinant has been the relative vulnerability of the small eutherian egg 
to polyspermy. In most eutherians, this problem is solved in a unique way by highly restrictive transport mediated by attachment of sperm to the epithelium of the oviduct isthmus, followed by a timed release of a very few up to the fertilization site. Such a sequence ensures that only very few sperm approach the unfertilised egg, in contrast to the crowds that do so in the amniotes and other vertebrates where physiological polyspermy is the rule. In many present-day Eutheria, however, that sperm paucity is offset by the cumulus that, by enhancing the egg-related target in a generally spacious ampulla, facilitates the meeting of sperm and eggs. However, it should not be missed that other options appeared during eutherian evolution, shrews at least having adopted radically different yet effective mechanisms of sperm regulation, induction of the $A R$, and sperm binding to the zona pellucida (Bedford, Mock and Goodman, 2004).

\section{References}

AUSTIN, C.R. AND BRADEN, A.W.H. (1952). Passage of the sperm and penetration of the egg in mammals. Nature 170: 919-920.

BABA, T.,AZUMA, S., KASHIWABARA, S AND TOYODA, Y. (1994). Sperm from mice carrying a targeted mutation of the acrosin gene can penetrate the oocyte zona pellucida and effect fertilization. J. Biol. Chem. 269: 31845-31849.

BEDFORD, J.M. (1967). Effects of duct ligation on the fertilizing ability of spermatozoa from different regions of the rabbit epididymis. J. Exp. Zool. 166: 271-282

BEDFORD, J.M. (1970). Sperm capacitation and fertilization in mammals. Biol. Reprod. 2: suppl. 2 - 128-158.

BEDFORD, J.M. (1978). Anatomical evidence for the epididymis as the prime mover in the evolution of the scrotum. Am. J. Anat. 152: 483-508,

BEDFORD, J.M. (2004) Enigmas of mammalian gamete form and function. Biol. Rev. 79: 429-460

BEDFORD, J.M., MOCK, O.B. and GOODMAN, S.M. (2004) Novelties of conception in insectivorous mammals (Lipotyphla), particularly shrews. Biol. Rev. 79: 891-909

BEDFORD, J.M. AND CROSS, N.L. (1978). Normal penetration of rabbit spermatozoa through a trypsin and acrosin-resistant zona pellucida. J. Reprod. Fert. 54: 385-392.

BEDFORD, J.M. AND YANAGIMACHI, R. (1991). Epididymal storage at abdominal temperature reduces the time for capacitation of hamster spermatozoa. $J$. Reprod. Fert. 91: 403-410.

BEDFORD, J.M. AND BREED, W.G. (1994). Regulated storage and subsequent transformation of spermatozoa in the fallopian tube of an Australian marsupial, Sminthopsis crassicaudata. Biol. Reprod. 50: 845-854.

BI, M., HICKOX, J.R., WINFREY, V.P., OLSON, G.E. AND HARDY, D.M. (2003). Processing, localization and binding activity of zonadhesin suggest a function in sperm adhesion to the zona pellucida during exocytosis of the acrosome. Biochem. J. 375: 477-488.

BIRKHEAD, T.R. (1998). Sperm competition in birds. Revs. in Reprod. 3: 123-129.

BOUÉ, F. AND SULLIVAN, R. (1996). Cases of human infertility are associated with the absence of $\mathrm{P} 34 \mathrm{H}$, an epididymal sperm antigen. Biol. Reprod. 54: 10181024.

BREED, W. G. (1993) Novel organization of the spermatozoon in two species of murid rodents from Southern Asia. J. Reprod. Fert. 99: 149-158.

BREED, W.G. (1994). Sperm-egg interactions in an Australian dasyurid marsupial with special reference to changes in acrosomal morphology. Zygote 2: 201211.

BREED W.G., HOPE, R.M., WIEBKIN O.W., SPARGO, S.C. AND CHAPMAN, J.A. (2002). Structural organization and evolution of the marsupial zona pellucida. Reprod. 123 : 13-21.

BRONSON, F. H. AND HEIDEMAN, P.D. (1993). Failure of cryptorchidism to suppress fertility in a tropical rodent. Biol. Reprod. 48: 1354-1359.

CARRICK F. N. AND SETCHELL, B.P. (1977). The evolution of the scrotum. In Reproduction and Evolution (eds. J.H. Calaby and C.H. Tyndale-Biscoe), pp.
165-170. Austr. Acad of Sci.

CHANG, M.C. AND PINCUS G. (1951). Physiology of fertilization in mammals. Physiol. Revs. 31: 1-26.

CHATURAPANICH, G., JONES, R.C. AND CLULOW, J. (1992). Role of androgen in survival of spermatozoa in the epididymis of tammar wallaby (Macropus eugenii). J. Reprod. Fert. 95: 421-429.

CLULOW, J. AND JONES, R.C. (1982). Production, transport, maturation, storage, and survival of spermatozoa in the male Japanese quail, Coturnix coturnix. J. Reprod. Fert. 64: 259-266.

CONTRERAS, L.C. AND ROSEMANN, M. (1982). Thermoregulation in the testes of Octodon degus, a non-scrotal rodent. Physiol. Zool. 55: 144-147.

CROSS, N.L. (1998). Role of cholesterol in sperm capacitation. Biol. Reprod. 59: 7-11.

DERR, P., YEUNG, C.H., COOPER, T.G., AND KIRCHHOFF, C. (2001) Synthesis and glycosylation of CD52, the major 'maturation-associated' antigen on rat spermatozoa in the cauda epididymidis. Reprod. 121: 435-446.

DENKER, H.W. (2000). Structural dynamics and function of early embryonic coats. Cells, Tissues, Organs. 166: 180-207.

ELLERMAN D.A., COHEN D.J., DA ROS, V.G., MORGENFELD, M.M. AND CUASNICU, P.S. (2006). Sperm protein 'DE' mediates gamete fusion through an evolutionarily conserved site of the CRISP family. Dev. Biol. 297: 228-237

EWING L.L. AND SCHANBACHER, L.M. (1970). Early effects of experimental cryptorchidism on the activity of selected enzymes in rat testes. Endocrinol. 87 : 129-134.

FLESCH, F. M. AND GADELLA, B.M. (2000). Dynamics of the mammalian sperm plasma membrane in the process of fertilization. Biochim. Biophys. Acta 1469:197-235.

FREEMAN, S. (1990). The evolution of the scrotum: a new hypothesis. J. Theor. Biol. 145: 429-445.

GABORIAU, D., HOWES, E.A., CLARK, J. AND JONES, R. (2007). Binding of sperm proacrosin/acrosin to zona pellucida glycoproteins is sulfate and stereodependent. Synthesis of a novel fertilization inhibitor. Dev. Biol. 306:646657.

HO, H.C. AND SUAREZ, S.S. (2001). Hyperactivation of mammalian spermatozoa: function and regulation. Reprod. 122:519-526.

HUNTER, R.H.F. (1996). Ovarian control of very low sperm/egg ratios at the commencement of mammalian fertilization to avoid polyspermy. Mol. Reprod. Dev. 44: 417-422.

HUNTER, R.H.F., HOLTZ, W. AND HENFREY, P.J. (1976). Epididymal function in the boar in relation to the fertilizing ability of spermatozoa. J. Reprod. Fert. 46: 463-466.

HUNTER, R.H.F., HOLTZ, W. AND HERMANN, H. (1978). Stabilizing role of seminal plasma in relation to the capacitation time of boar spermatozoa. Anim. Reprod. Sci. 1: 161-166.

HUNTER, R.H.F. AND LÉGLISE, P.C. (1971). Polyspermic fertilization following tubal surgery in pigs, with particular reference to the role of the isthmus. $J$. Reprod. Fert 24: 233-246.

JONES, R. (1998). Plasma membrane structure and remodeling during sperm maturation in the epididymis. J. Reprod. Fert. Suppl. 53: 73-84.

KLEMM, U., MULLER-ESTERL, W. AND ENGEL, W. (1991). Acrosin, the peculiar sperm- specific serine protease. Hum. Genet. 87: 635-641.

KOPECNY, V. AND FLECHON JE. (1987). Ultrastructural localization of labelled acrosomal glycoproteins during in vivo fertilization in the rabbit. Gam. Res. 17: 35-42.

LLANOS, M., VIGIL, P., SLAGADO, A.M., AND MORALES, P. (1993). Inhibition of the acrosome reaction by trypsin inhibitors and prevention of penetration of spermatozoa through the human zona pellucida. J. Reprod. Fert. 97: 173-178.

LILLIE, F.R. (1919). Problems of Fertilization. Univ. of Chicago Press, Chicago, III.

MCRORIE, R.A. and WILLIAMS, W.L. (1974). Biochemistry of mammalian fertilization. Ann. Rev. Biochem. 43: 777 - 798.

MEIZEL, S. (1984). The importance of hydrolytic enzymes to an exocytotic event, the mammalian acrosome reaction. Biol. Revs. 59: 125 - 157.

MOHRI, H. AND YANAGIMACHI, R. (1980). Characteristics of motor apparatus in testicular, epididymal, and ejaculated spermatozoa: a study using 
demembranated sperm model. Exp. Cell Res. 127: 191-196.

MOLLER, A.P. (1989). Ejaculate quality, testes size and sperm production in mammals. Func. Ecol. 3: 91-96.

OLSON, G.E., WINFREY V. P. AND NAGDAS, S.K. (2003). Structural modification of the hamster sperm acrosome during post-testicular development in the epididymis. In Microsc. Res. Techs. (ed. K. Toshimori). 61: 46-55.

OLSON, G.E., WINFREY, V.P., BI, M., HARDY, D.M. AND NAGDAS, S.K. (2004). Zonadhesin assembly into the hamster sperm acrosomal matrix occurs by distinct tagging strategies during spermiogenesis and maturation in the epididymis. Biol. Reprod. 71: 1128-1134.

OKABE, M. AND CUMMINS, J.M. (2007). Mechanisms of sperm-egg interactions emerging from gene-manipulated animals. Cell Mol Life Sci. 64:1945-1958.

OSHEROFF, J.E., VISCONTI, P.E., VALENZUELA, J.P., TRAVIS A. J. ALVAREZ, J. AND KOPF, G.S. (1999). Regulation of human sperm capacitation by a cholesterol efflux-stimulated signal transduction pathway leading to protein kinase A-mediated up-regulation of protein tyrosine phosphorylation. Hum. Mol. Reprod. 11: 1017-1026.

PINCUS G. (1936) The eggs of mammals. Macmillan, New York

RENFREE, M.B., HARRY, J.L. AND SHAW, G. (1995). The marsupial male: a role model for sexual development. Phil. Trans. Roy. Soc. London B. 350: 243-251.

RIFKIN, J. M. AND OLSON, G.E. (1985). Characterization of maturation-dependent extrinsic proteins of the rat sperm surface. J. Cel/ Biol. 100: 1582-1591.

ROBERTS, C.T., BREED, W.G. AND MAYRHOFER, G. (1994). Origin of the oocyte shell membrane of a dasyurid marsupial: an immunohistochemical study. $\mathrm{J}$. Exp. Zool. 270: 321-331.

RODGER, J.C. AND YOUNG, R.J. (1982). Glycosidase and cumulus dispersal activities of acrosomal extracts from opossum (marsupial) and rabbit (eutherian) spermatozoa. Gam. Res. 4: 507-514.

ROTHCHILD, I. (2003). The yolkless egg and the evolution of viviparity. Biol. Reprod. 68: 337-357.

ROZEN, S., SKALETSKY, H., MARSZALEK, J.D., MINX, P.J., CORDUM, H.S., WATERSTON, R.H., WILLSON, R.K. AND PAGE, D.G. (2003). Abundant gene conversion between arms of palindromes in human and ape $Y$ chromosomes. Nature 423: 873-876.

SALING, P. M. (1982). Development of the ability to bind to zona pellucidae during epididymal maturation: reversible immobilization of mouse sperm by lanthanum. Biol. Reprod. 26: 429-436.

SELWOOD, L. (2000). Marsupial egg and embryo coats. Cells, Tissues, Organs. 166: 208- 219 .
SHAMS-BORHAN, G., HUNEAU, D. AND FLECHON, J.E. (1979). Acrosin does not appear to be bound to the inner acrosomal membrane of bull spermatozoa. $J$. Exp. Zool. 209: 143-149.

SHORT, R.V. (1997). The testis: the witness of the mating system, the site of mutation, and the engine of desire. Acta Paed. Suppl. 422: 3-7.

SMITH, G.D., WOLF, D.P., TRAUTMAN, K.C., DA CRUZ E SILVA, E.F., GREENGARD, P. AND VIJAYRHAGAVAN, S. (1996). Primate sperm contain protein phosphatase 1, a biochemical mediator of motility. Biol. Reprod. 54 : 719-727.

SRIVASTAVA, P.N., ADAMS, C.E. AND HARTREE, E.F. (1965). Enzymic action of acrosomal preparations on the rabbit ovum in vitro. J. Reprod. Fert. 10: 61-67.

URSINI, F., HEIM, S., KIESS, M., MAIORINO, M., ROVERI, A., VISSING, J AND FLOHE, L. (1999). Dual function of the seleno-protein PHGPx during sperm maturation. Science 285: $1393-1396$.

WASSARMAN, P., CHEN, J., COHEN, N., LITSCHER, E., LIU, C., QI, H. AND WILLIAMS, S. (1999). Structure and function of the mammalian egg zona pellucida. J. Exp. Zool. 285: 251-258.

WERDELIN, L. AND NILSONNE, A. (1999) The evolution of a scrotum and testicular descent in mammals. J. Theor. Biol. 196: 61-72.

YANAGIMACHI, R. AND PHILLIPS, D.M. (1984). The status of acrosomal caps of hamster sperm immediately before fertilization in vivo. Gam. Res. 9: 1-20.

YEUNG, C-H., SCHROTER, S., WAGENFELD, A., KIRCHHOFF, C., KLIESCH, S., POSER, D., WEINBAUER, G.F., NIESCHLAG, E. AND COOPER, T.G. (1997) Interactions of human epididymal protein CD52 (HE5) with epididymal spermatozoa from men and cynomolgus monkeys. Mol. Reprod. Dev. 48: 267-275.

YEUNG, C.H., SCHROTER, S., KIRCHHOFF, C AND COOPER, T.G. (2000) Maturational changes of the CD52-like epididymal glycoprotein on cynomolgus monkey sperm and their apparent reversal in capacitation conditions. Mol Reprod. Dev. 57: 280-289.

YI Y-J, MANANADHAR, G., OKO, R., BREED, W.G., AND SUTOVSKY, P. (2007). Mechanism of sperm-zona pellucida penetration during mammalian fertilization: 26 s proteosome as a candidate egg coat lysin. Soc. Reprod. Fertil. Suppl. 63: 385-408.

YOSHINAGA, K. AND TOSHIMORI, K. (2003) Organization and modifications of sperm acrosomal molecules during spermatogenesis and epididymal maturation. Microsc. Res and Techs. (ed. K. Toshimori). 61: 39-45.

ZANEVELD, L.J.D. AND DE JONGE, C.J. (1991) Mammalian sperm acrosomal enzymes and the acrosome reaction. In A Comparative Overview of Mammalian Fertilization (eds. B.S. Dunbar and M.G. O'Rand) pp. 63 - 79. Plenum Press, New York. 


\section{Related, previously published Int. J. Dev. Biol. articles}

See our recent Special Issue Developmental Biology in Poland edited by Tarkowski, Maleszewski and Kloc at: http://www.ijdb.ehu.es/web/contents.php?vol=52\&issue=2-3

See our recent Special Issue Ear Development edited by Fernando Giraldez and Bernd Fritzsch at: http://www.ijdb.ehu.es/web/contents.php?vol=51\&issue=6-7

Mammalian fertilization:the egg's multifunctional zona pellucida

Paul M. Wassarman and Eveline S. Litscher

Int. J. Dev. Biol. (2008) 52: 665-676

Genetic control of gamete quality in the mouse - a tribute to Halina Krzanowska Jozefa Styrna

Int. J. Dev. Biol. (2008) 52: 195-199

Molecular aspects of avian oogenesis and fertilisation

Bozenna Olszanska and Urszula Stepinska

Int. J. Dev. Biol. (2008) 52: 187-194

Distinct mechanisms underlie sperm-induced and protease-induced oolemma block to sperm penetration.

Sebastian Komorowski, Katarzyna Szczepanska and Marek Maleszewski Int. J. Dev. Biol. (2003) 47: 65-69

CpZPC, a newt ZPC molecule, localizes to the inner surface of the egg envelope.

Youko Makabe-Kobayashi, Etsuko Kudaira, Akihiko Watanabe and Kazuo Onitake

Int. J. Dev. Biol. (2003) 47: 51-58

Teaching critical thinking in a developmental biology course at an American liberal arts college.

Dany S Adams

Int. J. Dev. Biol. (2003) 47: 145-151

Association of egg zona pellucida glycoprotein mZP3 with sperm protein sp56 during fertilization in mice.

2006 ISI **Impact Factor $=3.577^{\star *}$

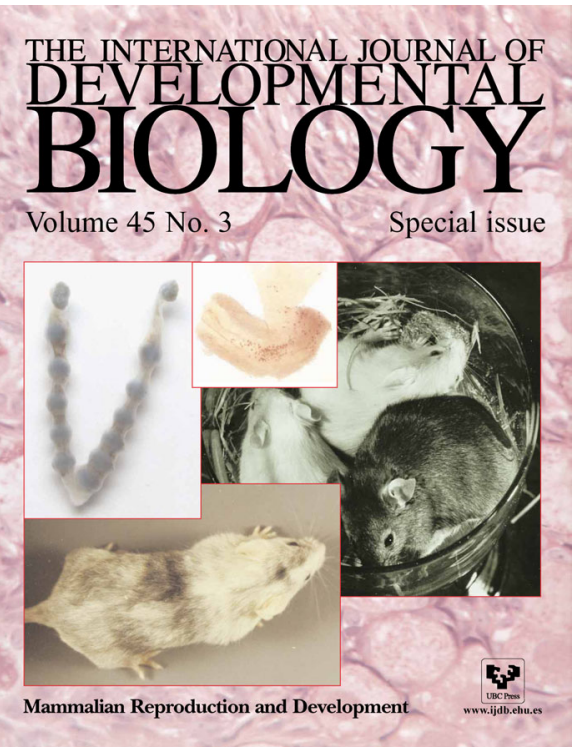

